\title{
Numerical Simulation of Combustion Chamber for Button Turbojet Engine
}

\author{
Hongpeng Ma, Shuzhou Fang, Hang Gao, Teng Li and Guanlin Fang \\ School of Aerospace Science and Engineering, Beijing Institute of Technology, Beijing,100081, China
}

\begin{abstract}
To provide reference data for ultra-micro combustor, a new type button turbojet engine was designed and simulated the combustion's steady-state process. The boundary condition of inlet was calculated using isentropic numerical calculation, taken into turbulent chemical reaction, heat radiation, and so on, getting the combustion chamber's steady-state of the velocity, temperature and component concentration distribution, analysis the fuel/air flow and backflow, combustion efficiency and total pressure recovery coefficient, and compared with the experimental data. The calculation results can accurately reflect the actual combustion. The results show that combustion chamber exit velocity is about $65 \mathrm{~m} / \mathrm{s}$, outlet temperature is around $1000 \mathrm{~K}$, the simulation and experimental data are similar, combustion chamber structure design is reasonable, and this paper will provide a basis for the future improvement of the millimeter scale turbojet engine.
\end{abstract}

\section{Introduction}

As a high energy density of tactical powerplant, Micro Turbojet Engine(MTE) can be applied to small UAV (Unmanned Aerial Vehicle ), target drone, cruise missiles and other kinds of MAV(Micro Aerial Vehicle). It will play an increasingly important role in the future air war, military reconnaissance, environment monitoring and even anti-terrorism operations, etc, [1]-[3]. However, combustion chamber as a key technology of MTE, due to the requirements of more and more miniaturization (millimeter level), there are many technical difficulties: (1) the structure size is too small to MEMS processing easily; (2) compared to normal engine, bigger surface-tovolume ratio will increase its heat loss; (3) burning resident time is short, easy to appear the incomplete combustion;(4) resistance factors are complicated, many process related to the structure size are diffenrent, such as fule injection, mixing of fluid mechanics, the flow field analysis will become more difficult, [4]-[6].

Up to now, both home and abroad researches are mainly concentrated on the study of micro turbojet engine's traditional structure design and improvement, [7]-[9], the flow field analysis of the micro small engines are very rare, millimeter turbojet engine's threedimensional flow field researches are basically in the blank stage. This paper discussion is based on the researches at home and abroad [10]-[15], design a round Button Turbojet Engine (BTE), and do some numerical simulations for the combustion chamber. Therefore, not only we got the combustion efficiency factors, characteristic curve and total pressure recovery coefficient, but also obtained the distribution of temperature, velocity and component concentration about the internal combustion chamber. This work will provide the foundation for the future development, processing and production of the micro turbojet engine's combustion chamber.

\section{Physical model and calculation method}

\subsection{Physical model}

Reference some of past design experience, restricted to small structure size and MEMS processing, combustion chamber structure was finally confirmed as follows: the combustion chamber is divided into six independent fanshaped combustion chamber, diffuser blade surface form the outer wall of the combustion chamber, combustion chamber cavity is composed of backflow region wall and the diffuser blade wall, choose the methane as fuel, each entrance of combustion chamber set an intake pipe. The overall vertical view of engine (XOZ plane) and one sixth engine structure as shown in Fig. 1 and Fig. 2 respectively.

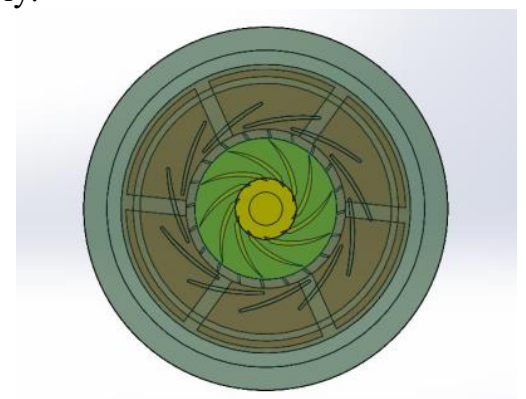

Figure 1. Overall vertical view of engine ( $\mathrm{XOZ}$ plane) 


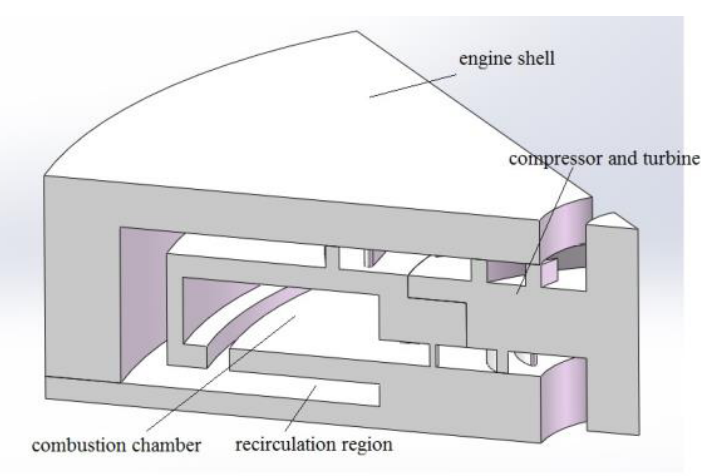

Figure 2. One sixth turbo engine structure

Combustor design dimensions are as follows: outer diameter $D_{1}=16.3 \mathrm{~mm}$, inner diameter $D_{2}=15.74 \mathrm{~mm}$, combustion chamber height $\mathrm{H}=1.2 \mathrm{~mm}$, each volume of the combustion chamber $V_{c}^{\prime}=22.692 \mathrm{~mm}^{3}$, total volume $V_{c}=136.152 \mathrm{~mm}^{3}$, outlet temperature of the combustion chamber designed for $1000 \mathrm{~K}$, affordable for turbine materials, another innovation is an U-shaped recirculation zone at the entrance of the combustion chamber in order to improve the stability of the combustion flame.

\subsection{Combustor thermodynamic calculation}

The design of thermodynamic parameters: inlet combustor temperature $T_{2}^{*}=400 \mathrm{~K}$, outlet combustor temperature $T_{3}^{*}=1000 \mathrm{~K}$, fuel initial temperature $T_{f}=350 \mathrm{~K}$, fuel mass flow rate $m_{f}=0.002(\mathrm{~kg} / \mathrm{s})$, the combustor oil-gas ratio $\sigma=0.0225$, methane combustion heat value $H_{u}=50.07(\mathrm{~kJ} / \mathrm{kg})$.

\subsection{Combustion model}

Calculation using the EBU-Arrhenius turbulent combustion model, this model takes into account the turbulence and chemical dynamic factors influence on chemical reaction rate. This model's average response rate is showed as following formula (1):

$$
\bar{w}=\min \left\{\overline{w_{s t}}, \overline{w_{s v}}\right\}
$$

where $\overline{w_{s t}}=C_{E B U} \rho g \varepsilon / k, \overline{w_{s v}}=A \rho^{2} Y_{1} Y_{2} \exp \left(-\frac{E}{T}\right), \overline{w_{s t}}$ is the response rate controlled by turbulence, $C_{E B U}$ is empirical constant, $g$ is determined by the corresponding transport equation, $\overline{w_{s v}}$ is response rate controlled by laminar flow.

\subsection{Radiation model}

Common thermal radiation model include Zone Method, Heat Flux, Discrete Transfer Method, Monte-Carlo
Method and the Discrete Coordinate Method, etc, [16]. This article choose the Discrete Transfer Method, because it is wider using in engineering application and has higher precision in sloving flow equation.

The radiation heat transfer's integro-differential equations is as following formula(2):

$$
s \cdot \frac{\partial l}{\partial x_{j}}=k_{a} I_{b}-\left(k_{a}+k_{s}\right) I+\frac{K}{4 \pi} \int \Phi(\Omega, \bar{\Omega}) I d \Omega
$$

where $I$ is radiation intensity, $I_{b}$ is black-body radiation intensity, $s$ is direction vector, $k_{a}$ is medium absorbance, $k_{s}$ is medium scattering coefficient, $\Phi(\Omega, \bar{\Omega})$ is phase function and show the scattering characteristics of spatial distribution.

\subsection{Turbulence model}

In this paper, using double combustion model to simulate the interior flow field, the Reynolds Number is based on the wall distance, $\operatorname{Re}_{y}=\frac{\rho \sqrt{k} y}{\mu}$. Where $k$ is turbulence energy, $y$ is the distance between computational grids and the wall, turbulence viscosity ratio and Reynolds number have direct ratio relations, taken the experience value between 1 to 10 , turbulence intensity $(I)$ can be calculated by the following formula(3) :

$$
I=0.16 \times(R e)^{(-1 / 8)}
$$

where $R e$ is Reynolds number, given by the study of Alan h. Epstein, et al, [17]. In high Reynolds number turbulence model, compared with standard $k-\varepsilon$ model, $k-\varepsilon / R N G$ model equation has a new additional generated item, it can improve the simulated result of complex rapid flow. In the calculation software of FLUENT, double-layer model through turbulence model combined with enhanced wall function. In order to guarantee the accuracy of calculation, the wall grid is encrypted, ensure wall boundary layer $y^{+}<5$, other parameters set as default.

\subsection{Computational zone, mesh and boundary conditions}

Because of the engine combustion chamber is divided into six same size single chamber, refer to Fig. 1. Computational zone is choosen to one sixth combustion chamber, using ICEM divides the unstructured grids, the total number of grids are 2431003, partial encryption, combustion chamber inlet conditions set on the basis of the compressor's integration simulation results, computational mesh as shown in Fig. 3.

Boundary condition setting :

- Adopt speed inlet conditions, the numerical simulation results of cold combustion flow field as the the 
combustion chamber's import speed border, get the entrance velocity vector distribution, and then adjust inlet velocity according to the residual gas coefficient, flow flux, import area, density and other conditions.

- Set pressure-outlet for outlet conditions.

- Two sides of sector surfaces are spin cycle boundary, the combustion chamber internal walls set as fluidstructure coupled wall.

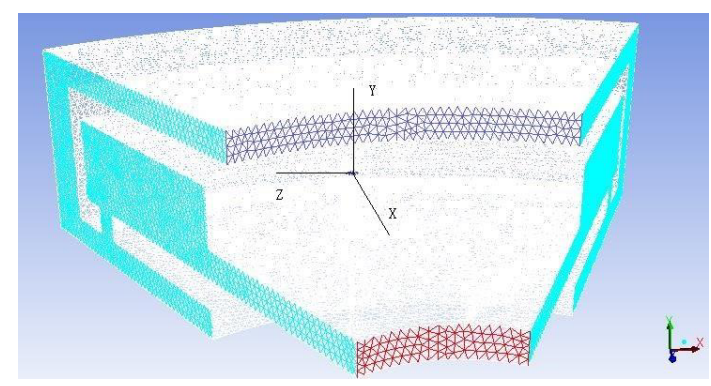

Figure 3. Computational mesh

\section{Calculation result}

Because the whole combustion chamber around $\mathrm{Y}$ axis is symmetrical rotation period, data analysis are mainly selected in $\mathrm{X}=0 \mathrm{~mm}$ cross section and $\mathrm{Y}=0.45 \sim 0.6 \mathrm{~mm}$ cross section whicn can reflect the combustion chamber internal component concentration and chemical reaction.

\subsection{Velocity field analysis}

Fig. 4 is the velocity distribution of $X=0 \mathrm{~mm}$ cross section which is the combustion chamber's center section. The figure shows that primary combustion zone is full of the whole combustion chamber, outlet velocity is about $65 \mathrm{~m} / \mathrm{s}$. Fig. 5 shows velocity nephogram marked primary combustion zone and backflow zone. As shown in Fig. 5, backflow zone exists at the entrance of the combustion chamber, which is beneficial to air to enter, improves the gas's burning time and the stability of the flame.

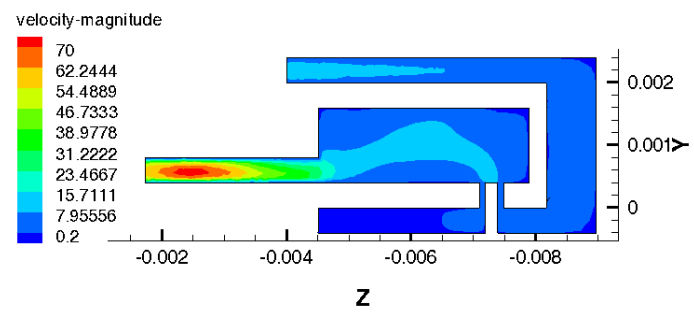

Figure 4. $X=0 \mathrm{~mm}$ cross section velocity nephogram

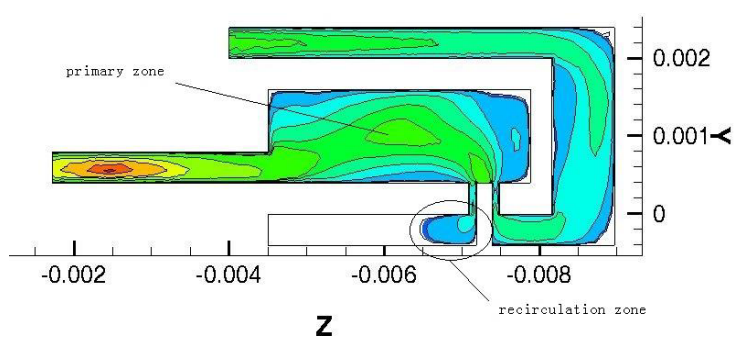

Figure 5. Marked primary zone and backflow zone of $X=0 \mathrm{~mm}$ cross section velocity nephogram
The following Fig. 6 is the velocity nephogram of $\mathrm{Y}=0.5 \mathrm{~mm}$ cross section. As seen in Fig. 6 , the exit of guide vane changed the originally vertical velocity vector into an angle of oblique direction which is perpendicular to the export turbine rotor blade surface, the high-speed fule gas impact the turbine rotor and get the power for driving the compressor.

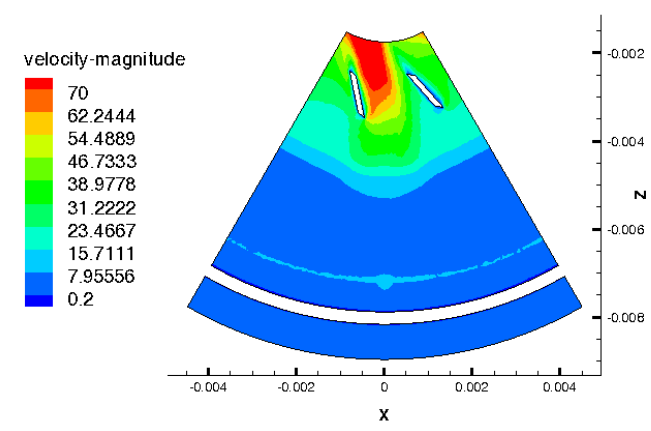

Figure 6. $\mathrm{Y}=0.5 \mathrm{~mm}$ cross section velocity nephogram

\subsection{Temperature field analysis}

In order to analyze the main combustion distribution area, select multiple consecutive cross section and semi-section $\mathrm{X}=0 \mathrm{~mm}$ for the whole flow field's temperature analysis. The selected cross sections are $\mathrm{Y}=0.45 \mathrm{~mm}, \mathrm{Y}=0.5 \mathrm{~mm}$, $\mathrm{Y}=0.55 \mathrm{~mm}$ and $\mathrm{Y}=0.6 \mathrm{~mm}$. Fig. 7 Fig. 12 show the temperature nephogram respectively. As seen in these figures, burning mainly concentrate in the region of the $\mathrm{Y}=0.4 \sim 0.6 \mathrm{~mm}$, the mixture of fuel and air combust sufficiently, the highest temperature is $1800 \mathrm{~K}$, the average temperature is about $1000 \mathrm{~K}$. Burning area presents a fan-shaped distribution, fit with the shape of combustion chamber design, and the wall temperature distribute uniformly, even there is no centralized hot point, all of these prove the rationality of the design of the combustion chamber powerfully.

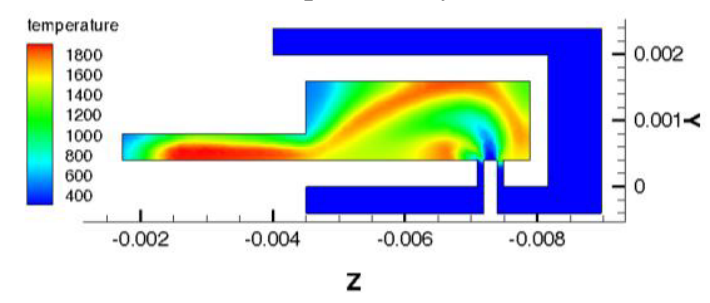

Figure 7. $\mathrm{X}=0 \mathrm{~mm}$ cross section temperature nephogram

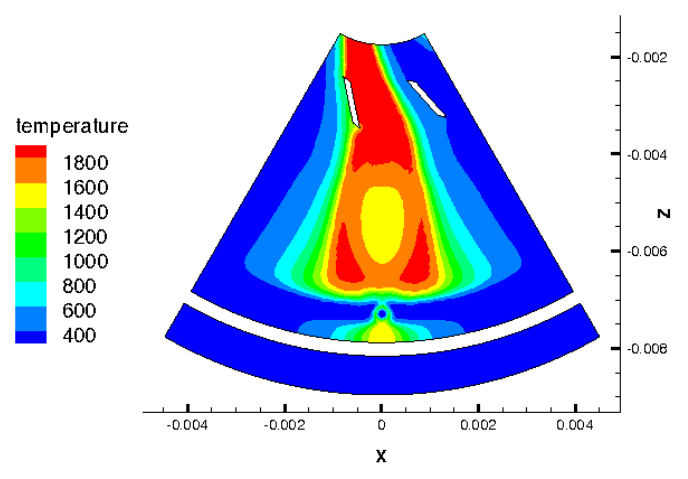

Figure 8. $\mathrm{Y}=0.45 \mathrm{~mm}$ cross section temperature nephogram 


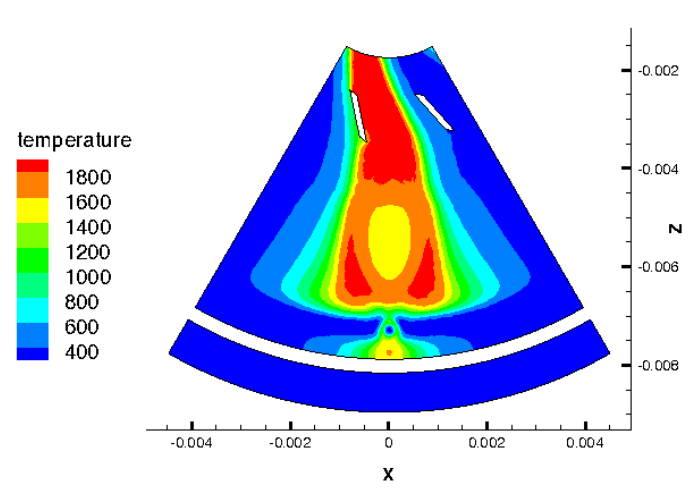

Figure 9. $\mathrm{Y}=0.5 \mathrm{~mm}$ cross section temperature nephogram

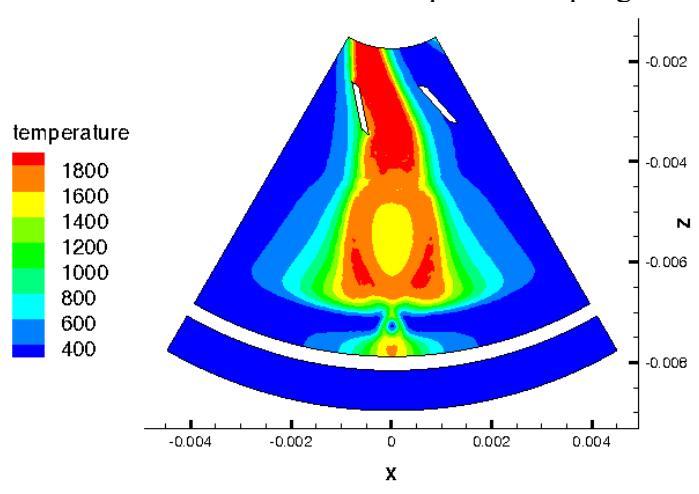

Figure 10. $\mathrm{Y}=0.55 \mathrm{~mm}$ cross section temperature nephogram

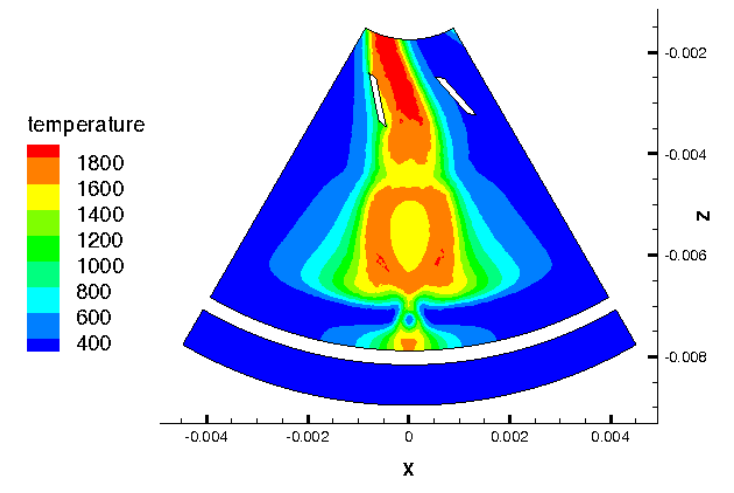

Figure 11. $Y=0.6 \mathrm{~mm}$ cross section temperature nephogram

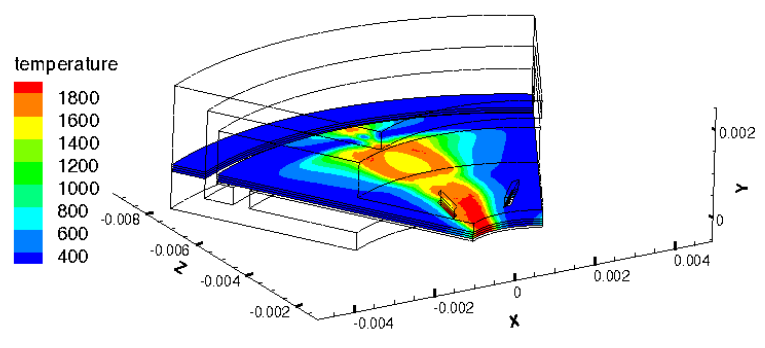

Figure 12. $Y=0.45 \sim 0.6 \mathrm{~mm} 3 \mathrm{D}$ temperature nephogram

\subsection{Component concentration field analysis}

Take the fuel inlet section $\mathrm{X}=0 \mathrm{~mm}$ and $\mathrm{Y}=0.5 \mathrm{~mm}$ cross section which can perfectly present the main combustion area to analyze the concentration of components. Fuel components of $\mathrm{CH}_{4}$ concentration distribution as shown in Fig. 13 and Fig. 14, it is observed that the highest fuel concentration centres on these areas of $\mathrm{Y}=0.4 \sim 0.6 \mathrm{~mm}$. Combustion occurs in the primary zone, totally accord with the former analysis data of temperature. As the axis distance increase, burning is ongoing, fuel concentration is getting lower and lower. The outlet fuel mass fraction is very small, fuel combustion efficiency is above $90 \%$, it is proved that the overall design of the combustion chamber is reasonable.

Fig. 15 distribution of $\mathrm{O}_{2}$ concentration in the section of $\mathrm{Y}=0.5 \mathrm{~mm}$, it can be seen the concentration distribution is in a triangular shaped diffusion, so as to ensure the stability of combustion. Fig. 16 and Fig. 17 are for the concentration distribution of combustion products of $\mathrm{CO}_{2}$ and $\mathrm{H}_{2} \mathrm{O}$ components, the concentration distribution in the diagrams proves once again the position of theoretical main combustion zone.

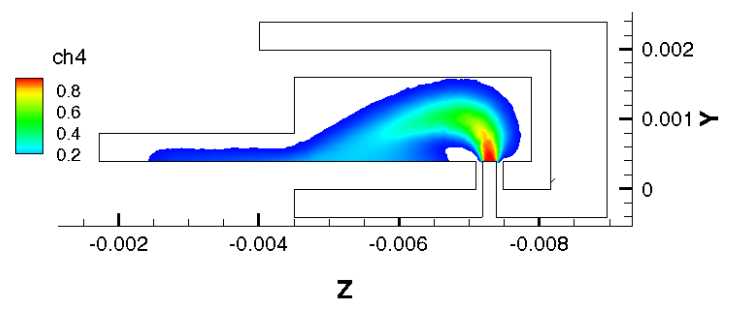

Figure 13. $\mathrm{X}=0 \mathrm{~mm}$ cross section $\mathrm{CH}_{4}$ concentration distribution

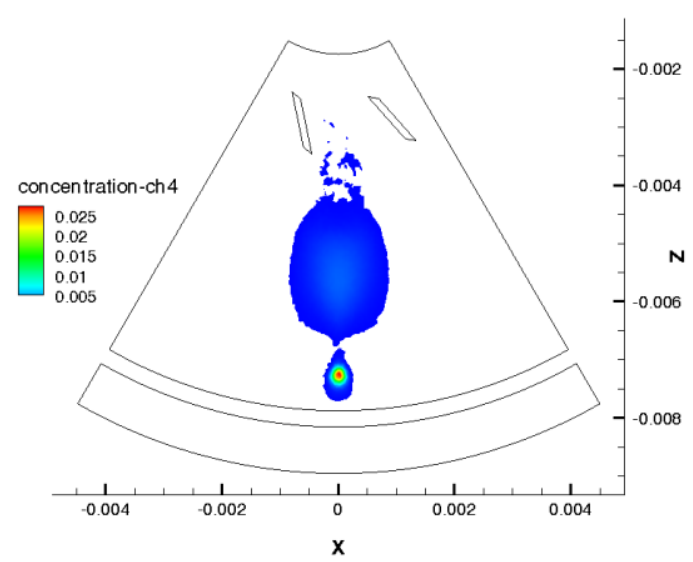

Figure 14. $\mathrm{Y}=0.5 \mathrm{~mm}$ cross section $\mathrm{CH}_{4}$ concentration distribution

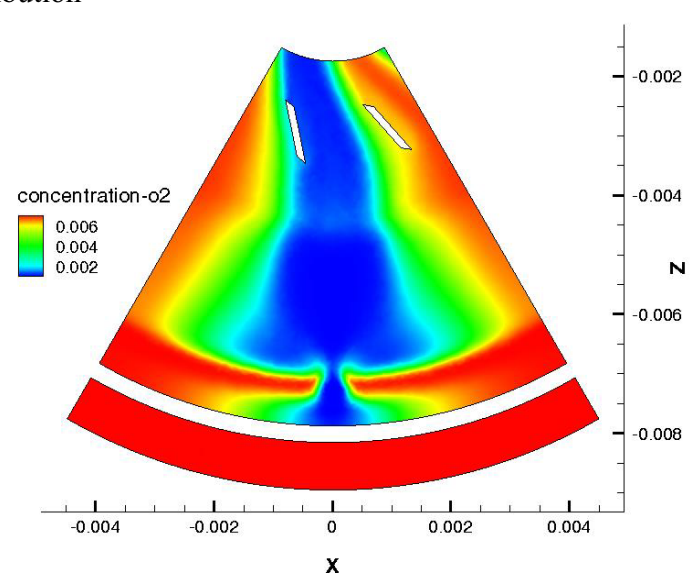

Figure 15. $\mathrm{Y}=0.5 \mathrm{~mm}$ cross section $\mathrm{O}_{2}$ concentration distribution 


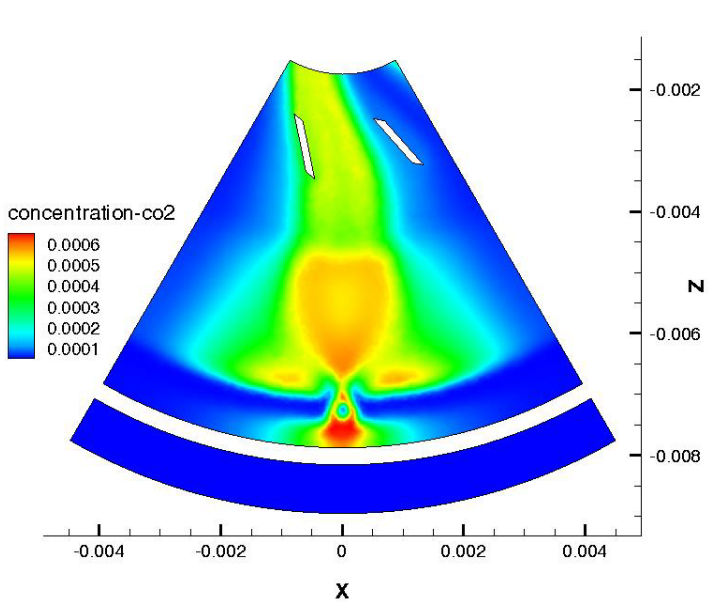

Figure 16. $\mathrm{Y}=0.5 \mathrm{~mm}$ cross section $\mathrm{CO}_{2}$ concentration distribution

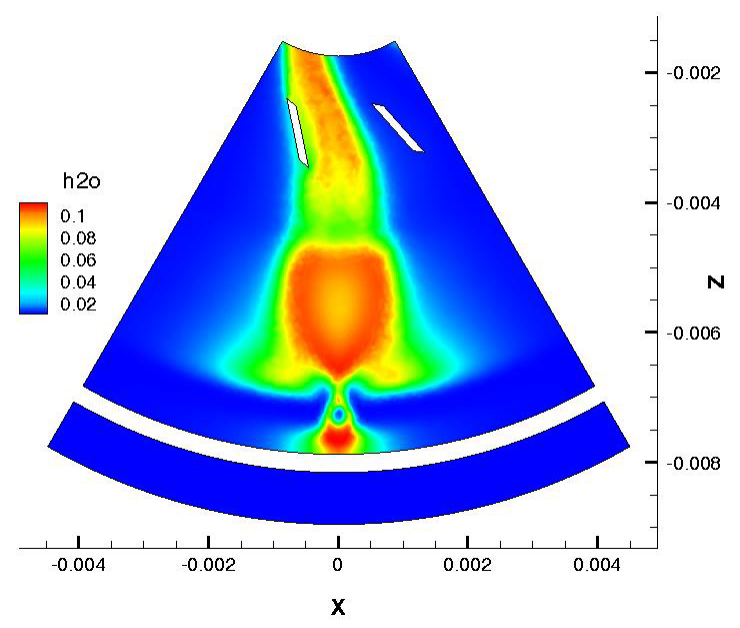

Figure 17. $\mathrm{Y}=0.5 \mathrm{~mm}$ cross section $\mathrm{H}_{2} \mathrm{O}$ concentration distribution

\subsection{Calculation and analysis of performance parameters of combustion chamber}

It can be concluded that the main performance parameters of the combustion chamber are as follows:

- Total pressure recovery coefficient $\sigma_{c}$

$$
\sigma_{c}=\frac{P_{3}^{*}}{P_{2}^{*}}
$$

In the formula (4), $P_{3}^{*}$ and $P_{2}^{*}$ respectively represent the average total outlet-pressure and the average total inlet-pressure. By calculating $\sigma_{c}=0.9$.

-Total volumetric heat intensity $Q_{V c}$

$$
Q_{V_{c}}=\frac{3600 \eta_{c} m_{f} H_{u}}{P_{2}^{*} V_{c}}=6238.3 \mathrm{~kJ} /\left(\mathrm{m}^{3} \cdot \mathrm{Pa} \cdot \mathrm{h}\right)
$$

volumetric heat intensity is bigger than common turbojet engines, This is because the volume of the new type of turbojet engine chamber is smaller, surface-to-volume ratio is bigger, the combustion residence time is much shorter and the flow resistance increases exponentially caused by the smaller size of the combustion chamber. But the change trend of the combustion efficiency characteristic is not very different from the common ones. It should be pointed out, although through the calculation, the combustion efficiency can reach $90 \%$, but in fact, due to the micro-scale viscous resistance and combustion residence time of various factors influence, the actual combustion efficiency inevitably reduce.

\subsection{Comparative analysis of experimental data}

Because of the limit of the MEMS processing and material cost and other aspects of the conditions, at present home and abroad in terms of this new button type turbojet engine ((combustion chamber diameter in $20 \mathrm{~mm})$, there is no actual experiments for comparison, so this paper chooses existing the experimental data of micro turbojet engine (combustion chamber diameter in $50 \mathrm{~mm}$ to $100 \mathrm{~mm}$ ) and the theoretical study of Massachusetts Institute of Technology in micro turbojet as the contrast, the selected data are as follows: (1) a study on tiny annular combustion chamber by Nanjing University of Science and Technology (NUST)(combustion chamber diameter is $50 \mathrm{~mm})$, [18]. (2) a micro turbojet engine study by Beijing Institute of Technology (BIT) (the outer diameter of the combustion chamber is 70mm), [19]. (3) research on micro turbojet based on MEMS processing method by the Massachusetts Institute of Technology (MIT), [17]. The compared data are shown as Table 1.

Table 1. Simulation and experiment contrast

\begin{tabular}{ccccc}
\hline & NUST & BIT & MIT & BTE \\
\hline$\sigma_{c}$ & 0.98 & 0.9 & $>0.9$ & 0.9 \\
$Q_{V c}$ & 3895 & 3980 & $*$ & 6238.3 \\
$\eta$ & 0.93 & 0.91 & $>0.9$ & 0.9 \\
\hline
\end{tabular}

From the table, the total pressure recovery coefficient, volumetric heat intensity and combustion efficiency and so on is in the reasonable range, it shows that the design of the button type turbine engine design is reasonable. Limited by the MEMS processing technology and experimental conditions, only do some simulation research work at present, the follow-up will eventually need to go through the test of unity machine working condition. The research of this paper has certain reference value for the design and improvement of the future ultramicro turbojet engine.

\section{Conclusion}

In this paper, a new combustion chamber model was designed and simulated based on the conventional micro turbine engine, realizing the integration simulation of working process in atmospheric environment and getting the following conclusions :

(1) The average velocity of the combustion chamber outlet is $65 \mathrm{~m} / \mathrm{s}$, the combustion chamber outlet 
temperature is about $1000 \mathrm{~K}$, fuel and air are mixed evenly, the combustion is sufficient.

(2) The combustion chamber is segmentation for six of the same fan combustion chamber, respectively of fuel supply, effectively guarantee the reliability of the engine's thrust. And there is a recirculation zone at the entrance of the combustion chamber, which can effectively promote the stability of the flame. Also the wall temperature is well-distributed, no obvious hot spots.

(3) The simulation data are compared with the experimental and simulation data of the domestic and foreign engine. The results show that the design of the button type engine is reasonable.

(4) One approach to realizing BTE utilizes the micromachining technology known as MEMS, the process impact of these engines will be dependent on the performance levels and the manufacturing costs. It's possible that BTE may be competitive with conventional machines. It will be very useful as power sources for small aero\&space vehicles.

\section{References}

1. Liang D W, Huang G P. Recent Development and Key Techniques of Micro Turbine in Centimeter Size. Gas Turbine Experiment and Research, 17(2):9-13, (2001).

2. Yuan P Y. The Present Situation and Development Prospect of Micro Turbine Engine. International Aviation, 71996

3. S.W. Janson, H. Helvajian, MEMS, Microengineering and Aeiospace Systems. AIAA, 99-3802.

4. Li C, Fang S Z, Zhang P. Numerical Simulation of Annular Combustion Chamber for Micro Turbine Engine. Journal of Propulsion Technology, 5:513518, (2008)

5. Jacobson S A. Aero-thermal challenges in the design of a micro-fabricated gas turbine engine. AIAA, 982545.

6. Saburo Y, Kana O. Concept and experiment of a flatflame micro combustor for ultra micro gas turbine. AIAA, 2002-3771.

7. Yuan Y Z, Wang L P, Guan L W. Numerical Simulation and Optimization od A Micro Annular
Combustor. J Tsinghua Univ (Sci\&Tech), 2:198201+209, (2007)

8. Amit, et al. A Six-Wafer Combustion System for a Silicon Micro Gas Turbine Engine. Journal of Micro-electromechanical Systems, 9-4, (2000)

9. Stuart A. Jacobson. Aero-thermal challenges in the design of a micro-fabricated gas turbine engine, Albuquerque: $29^{\text {th }}$ AIAA Fluid Dynamics Conference, 98-2445.

10. A. H. Epstein, S. D. Serturia, et al. Micro-heat engines, gas turbines, and rocket engines-The MIT micro-engine project. Snowmass Village: $28^{\text {th }}$ AIAA Fluid Dynamics Conference, 97-1773.

11. C. M. Spadaccini, et al. High Power Density Silicon Combustion Systems for Micro Gas Turbine Engines, Journal of Engineering for Gas Turbines and Power,: 125: 709-719, (2003)

12. P. J. Conelho. Numerical Simulation of a Mild Combustion Burner. Combustion and Flame, ,124: 503-518, (2001)

13. Denis Veynante, Luc Vervisch. Turbulent combustion modeling, Progress in Energy and Combustion Science, 28:193-266, (2002).

14. Jinsong Hua, Meng Wu, Kurichi Kumar. Numerical Simulation of The Combustion of Hydrogen-Air Mixture in Micro-Scaled Chambers. Part I: Fundamental study, Chemical Engineering Science,: 60:3497-3506, (2005)

15. Jinsong Hua, Meng Wu, Kurichi Kumar. Numerical Simulation of The Combustion of Hydrogen-Air Mixture in Micro-Scaled Chambers. Part II: CFD analysis for a micro-combustor, Chemical Engineering Science, 60:3507-3515, (2005)

16. Wen Z, Shi L Y, Ren Y R. FLUENT Fluid Computing Applications Course, Tsinghua University Press, 1 (2009)

17. Alan H. Epstein. Millimeter-Scale, Micro-ElectroMechanical Systems Gas Turbine Engines, Journal of Engineering for Gas Turbines and Power, 126:205-226, (2004)

18. Wang D. Experimental Study of Micro Turbojet Engine, Nanjing University of Science and Technology, (2011)

19. Li C. The Design and Numerical Simulation Performance of Micro Turbojet Engine, Beijing Institute of Technology, (2008) 